\title{
A Regression Discontinuity Analysis of a Remedial Education Programme
}

\author{
ABRAHAM S. ROSS* and BETH LACEY**
}

\begin{abstract}
To demonstrate the usefulness of programme evaluation within the university a regression discontinuity design was used to assess the impact of a remedial education programme. Using multiple regression and analysis of covariance, credit course grades of students who had been enrolled in the remedial programmes were compared to the credit course grades of non-remedial students. The results indicated that the remedial programmes were not improving performance above what would have been expected based on high school marks.
\end{abstract}

\section{RÉSUMÉ}

En vue de démontrer l'utilité d'un programme d'évaluation au sein de l'université, un modèle de courbe discontinue et régressive a été utilisé pour évaluer l'impact d'un programme de rattrapage. $A$ partir d'un modèle de régression multiple et d'analyse de coefficient de variance les notes obtenues par les étudiants en rattrapage dans les différentes unités de valeur, ont été comparées aux notes obtenues dans les différentes unités de valeur par les étudiants d'un programme normal. Les résultats ont montré que le programme de rattrapage n'améliorait pas de manière substantielle les performances auxquelles on aurait pu s'attendre en se basant sur les notes obtenues au niveau secondaire.

In times of financial restraint it becomes increasingly important for institutions to examine their programmes to insure that they are receiving the greatest benefit possible from the money which they are spending. It is the current climate of financial restraint which is contributing to the growth of programme evaluation within both government and the private sector. While programme evaluation is being taught in a number of universities across Canada there do not appear to be many cases of its being used to examine university programmes themselves.

* Memorial University of Newfoundland

** University of Waterloo 
The present article considers one type of programme evaluation, impact assessment, and shows how it can be used to evaluate a university programme. The object of an impact assessment is to determine whether or not a programme is meeting its goals. Although the optimal method of impact assessment involves randomly assigning respondents to treatments, outside of a laboratory this is not always feasible. When random assignment is not feasible the second method of choice is "Quasi-Experimental" designs (Campbell and Stanley, 1966). Regression discontinuity is one method of quasi-experimental design which is well suited to evaluate academic programmes but which has not been utilized to any great extent. Regression discontinuity was first discussed in Campbell and Stanley (1966) and enlarged upon in Cook and Campbell (1979). Cook and Campbell class regression discontinuity as a quasi-experimental design with a non-equivalent control group and consider it to be well suited to evaluating the consequences in situations in which a group in need is given a compensatory treatment. In particular, the design can be used in cases where the members of a population can be placed on a continuum and where a cut-off point is used to assign subjects to the different treatments.

As Cook and Campbell indicate, the logic behind the design is simple. If the treatment is affecting performance then there should be a discontinuity at the cut-off point when the separate regression lines are computed for the two groups. The outcome of two hypothetical remedial courses, $\mathrm{X}$ and $\mathrm{Y}$ are plotted in Figure 1. High school marks in the subjects are plotted on the horizontal axis and scores in the university credit courses (taken after the remedial course) are plotted on the vertical axis. As can be seen, in course $\mathrm{X}$ there is no discontinuity at the cut-off point, therefore the remedial course has not affected performance. On the other hand, in course $Y$ there is a discontinuity which results from the improved performance of those below the cut-off point.

There is one major threat to the internal validity of the regression discontinuity design. If the interaction of selection and maturation results in a non-linear relationship between the pre and post scores, simply fitting regression lines to the two sides of the cut-off point could lead to the appearance of a discontinuity where none really existed. For example, students who were delayed in their cognitive development might set low marks in high school and be assigned to remedial courses. Their later improvement would appear to be due to the remedial courses when it was, in fact, attributable to their late maturity.

The regression discontinuity design can be used to measure the impact of a number of academic programmes. For instance, early admissions programmes for those whose high school preparation appears to be far above average or academic upgrading programmes for those whose high school preparation appears to be considerably below average. Another example of its use is given in Cook and Campbell who cite a study where regression discontinuity was used to determine whether being on a "Dean's List" for academic excellence affected academic performance in subsequent semesters. 


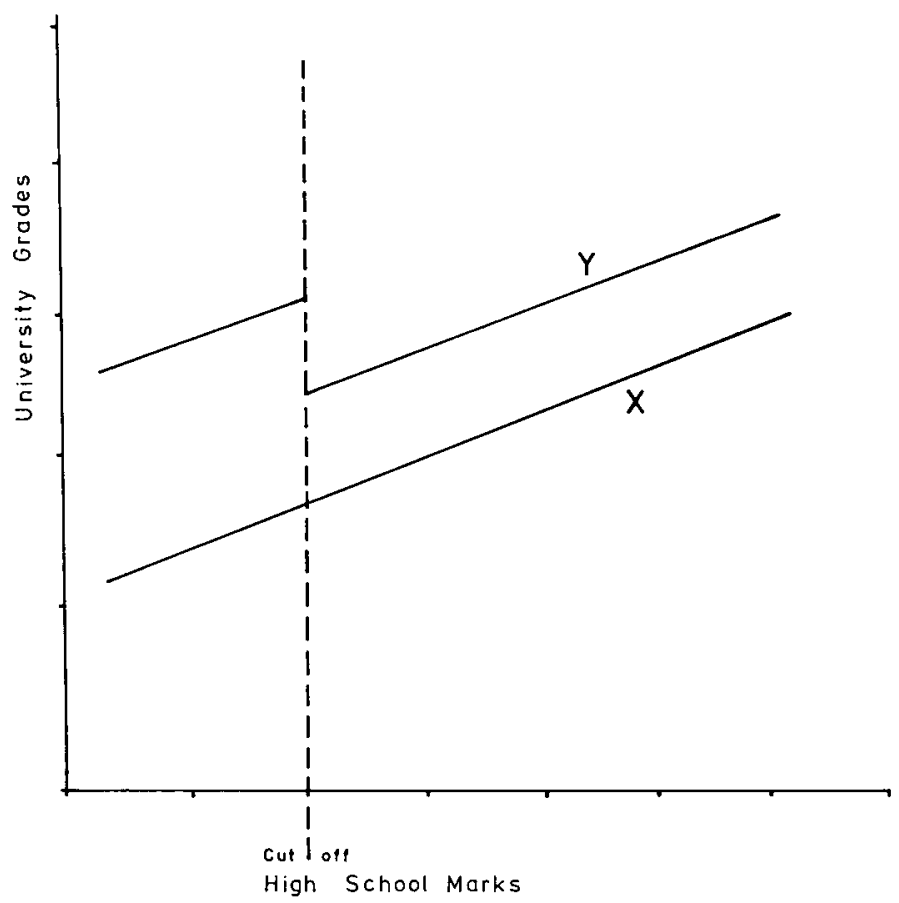

Figure 1 University grades plotted against high school marks in two hypothetical courses, $X$ and $Y$.

In this article we report an evaluation in which a regression discontinuity design was used to determine whether or not a remedial education programme was successful at improving students' grades in subsequent courses. The remedial education programme evaluated (called "foundation courses") consisted of one semester university courses which did not carry any academic credit. In general, students who have not achieved a high mark in a discipline above that recommended by a department or who have not taken a particular course in high school are compelled to complete the foundation course in the discipline before going on to a credit course in that area. The goals of the programme are to improve the student's marks in the credit course and to improve their chances of completing university successfully.

\section{SAMPLE}

The data used in this evaluation were collected from first year students files from 1977, 1978 and 1979. From an alphabetical listing of students the first name was selected randomly and every fourth subsequent name was sampled. High School Grade 11 marks and first semester and second semester grades were recorded for English, Mathematics, Chemistry, Biology and Physics. ${ }^{2}$

The sample consisted of 978 students, of whom 941 were enrolled in English, 626 in Mathematics, 295 in Biology, 291 in Chemistry and 216 in Physics. 
Seventy-five percent of the students in the sample were not enrolled in any foundation courses; $15 \%$ were enrolled in one foundation course, $5 \%$ in two foundation courses, $3 \%$ in three foundation and .3\% (3 students) in four foundation courses.

The data analysis was divided into two sections, which we will call the primary analysis and the secondary analysis. The primary analysis evaluated the performance of only those students who had taken the foundation subject in Grade 11. ${ }^{3}$ This analysis compared the performance of students in the foundation course who were below the cut-off line to the performance of students in the credit course who were above the cut-off line. The secondary analysis examined the effect of the foundation course on students who had not taken the subject in high school and thus were encountering the material for the first time. This analysis is considered "secondary" because the number of students in each analysis tended to be small and the results more tentative.

Lack of clarity about the minimal grade which a department requires for admission to a credit course can create difficulty in interpreting the results of a regression discontinuity analysis. For this reason the minimal grade standard for each course for each year was established empirically. For each foundation course for each year, the lowest Grade 11 mark, above which no students were put in the foundation course, was determined and designated as the "cut-off" point. Not all students scoring below a cut-off point are assigned to a foundation course. Those who have a recommendation from a high school principal or an overall Grade 11 average of 75 are allowed to take the credit course. As well, those who score a high mark on a placement test given in the first week of classes are moved into the credit course. Of the students whose high school grades were below a cut-off in a subject: $59 \%$ were put directly into the credit English course; $52 \%$ were put directly in the credit Mathematics course; $19 \%$ were put into the credit Biology course and $48 \%$ were put into the credit Chemistry course. These students were excluded from the primary analysis in order to avoid ambiguity in the results. Their performance was evaluated in the secondary analysis.

It is quite likely that the placement test is functioning as a "screening device" with better students being allowed out of the foundation programme and worse students remaining. It is, however, the remaining population which suffers from being required to enroll in a non-credit course and it is this population whose performance must be improved.

For the primary analysis students below the cut-off point who were enrolled in foundation courses were compared to students in the regular first credit courses whose Grade 11 marks were above the cut-off point using multiple regression. The two groups were compared on their performance in the normal first credit course, taken by foundation students in the second semester and by non-foundation students in the first semester. The problem with this comparison is that the performance of students who are more mature, by virtue of their being in their second semester of university, is being compared to the performance of students who are in their first semester of university and possibly less mature. If it was 
Regression and Analysis of Variance Models

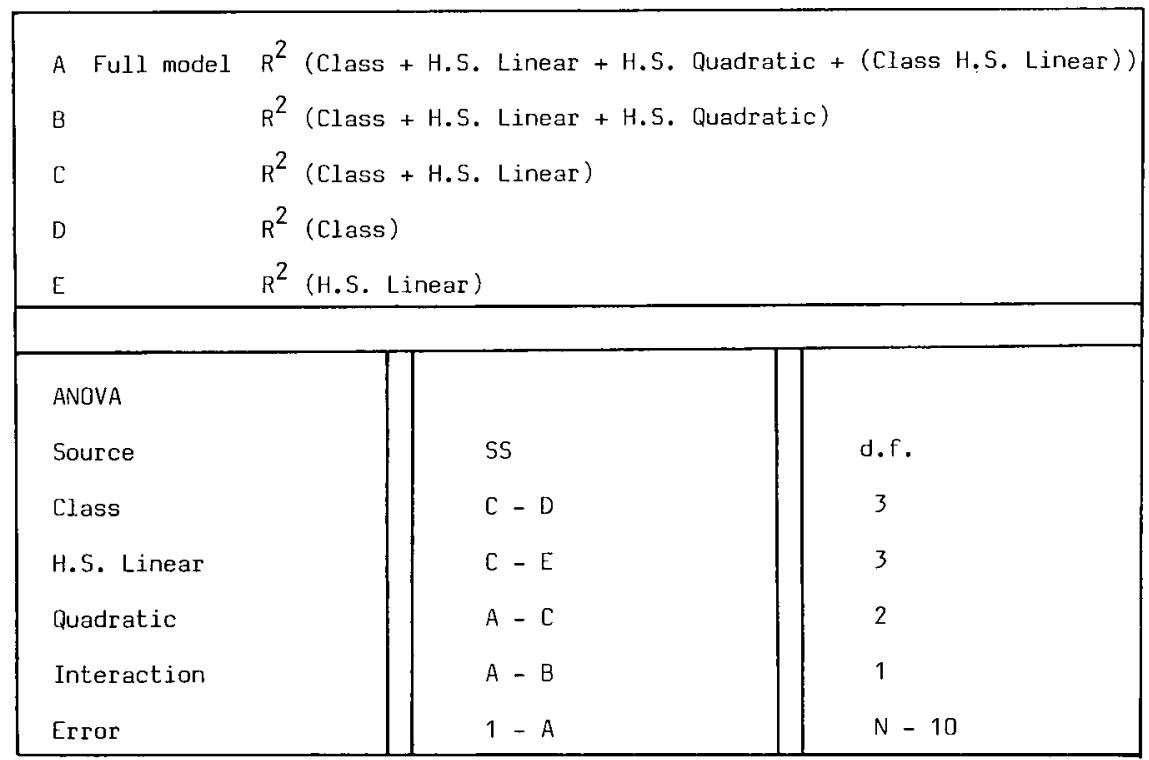

found that the performance of foundation students had improved, maturity would have to be considered as an alternate explanation.

To analyse the grades of the different groups in the primary analysis multiple regression was used. Using multiple regression it is possible to determine how much of the overall variance in the regression equation is accounted for by each of the components independently. This is accomplished by starting with a regression equation which includes all components (total model) and removing each component in turn. The reduction in $\mathrm{R}^{2}$ as each component is removed indicates how much it contributed to the overall variance. The basic model included high school scores in a subject (linear) and the course in which the student was enrolled (foundation or non-foundation). Since non-linearity is a serious threat to the internal validity of the design, the quadratic or non-linear component and the interaction between the components were included in the total model.

In the present application the interaction was removed first and then the quadratic component. After these two threats to the internal validity were removed without being replaced, the independent effects of the high school (linear) and class were removed and replaced. (See Table 1)

Whether or not the variance which each component contributes is significant can be determined by using the variance unaccounted for by the entire equation $\left(1-R^{2}\right)$ as an estimator of the sum of squares of the error term. If the variance contributed by the interaction was significant then the slopes of the regression 


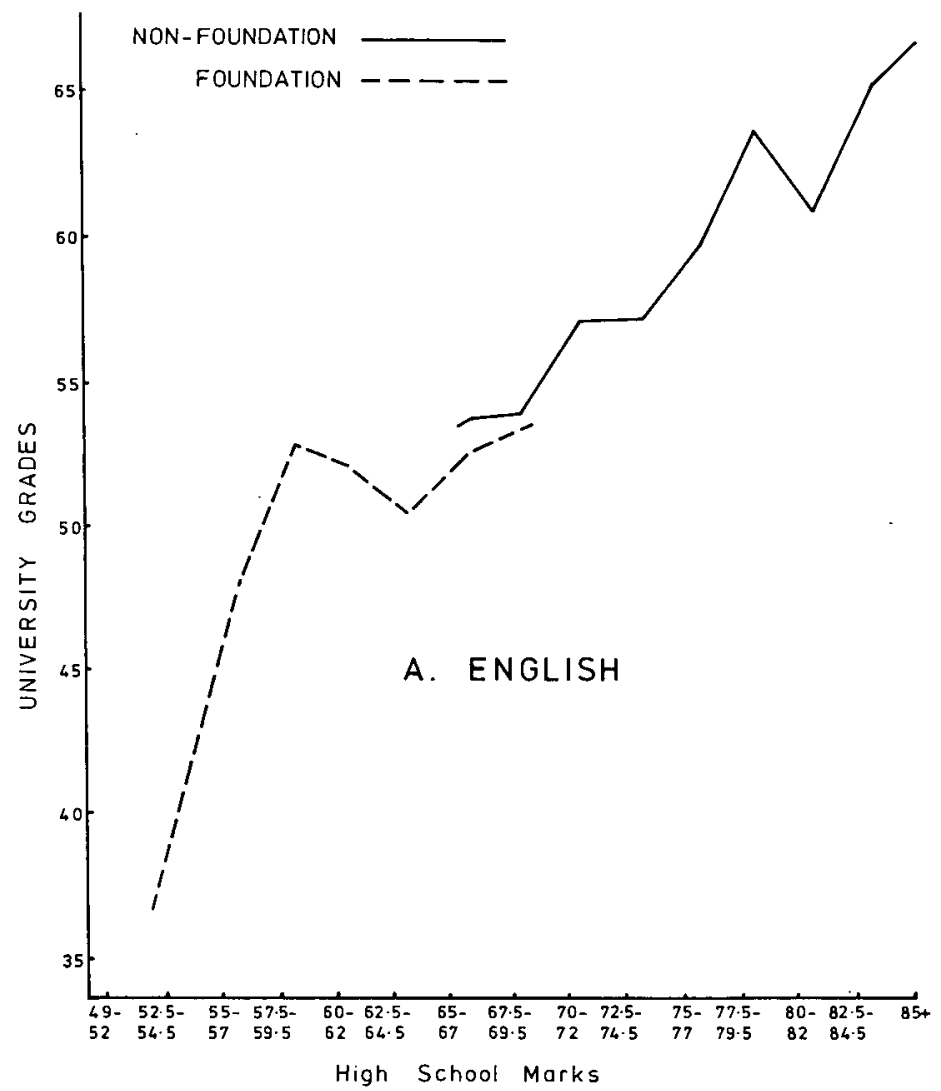

Figure 2A University grades plotted against high school marks in English.

lines of the two treatment groups were not parallel. Further, if the variance contributed by the quadratic component was significant then it is likely that the interaction was due to a curvilinear relationship between high school marks and university grades in subject area.

\section{Primary Analysis}

\section{RESULTS}

English: Four hundred and eleven students were enrolled in the English credit course in the Fall and 110 in the foundation course. Of this latter group, 10 failed the course and reenrolled in the Winter semester, 31 dropped the course (and apparently left university) and 70 students enrolled in the credit course offered in the Winter. The relationship between Grade 11 English marks and university English marks in the credit course, for foundation and non-foundation students, can be seen in Figure 2A.

As can be seen in Table 2, the full model accounts for slightly more than $25 \%$ of the variance in university English grades. The interaction was not significant $(\mathrm{F}<1)$ which means that the slope $(.76)$ of the grades which the foundation 


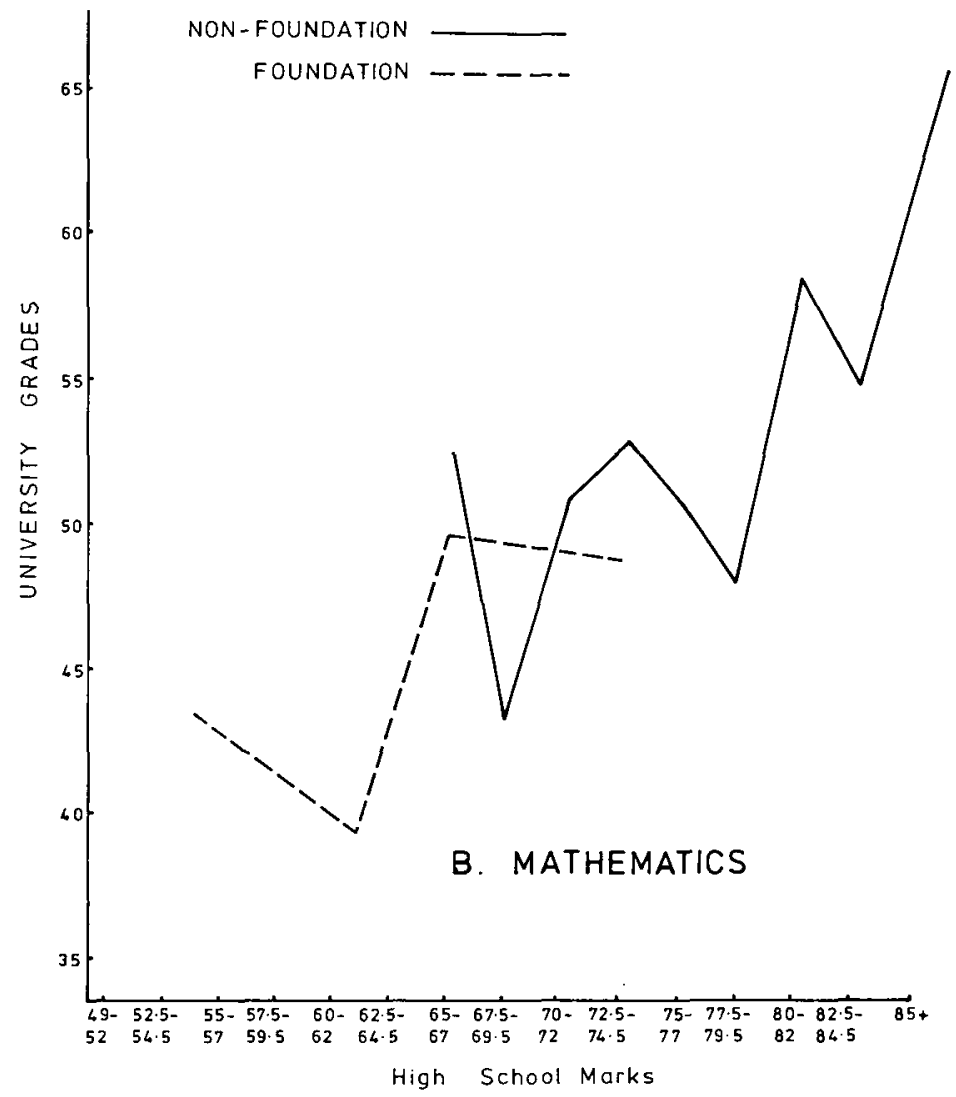

Figure 2B University grades plotted against high school marks in Mathematics.

students obtained in their first English credit course was not significantly different from the slopes (.68) of the Fall credit course grades. Removing the quadratic component from the equation indicates that it contributed less than $1 \%$ of the variance $(F<1)$. Removing the course from the equation and leaving the linear component reduces the variance accounted for by less than $1 \%$ also $(F<1)$. Thus, university grades were not related to which of the courses the student had taken (foundation-credit adjusted mean $=59.03$, credit adjusted mean $=58.23$; $\mathrm{F}<1$ ). However, when the linear component was removed and only the course was left, the variance was reduced by $14 \%$. The linear relationship between high school grades and university grades was the only significant contributor to the overall variance $(F=31.64 ; \mathrm{d} . f .=3,469 ; \mathrm{p}<.01)$. This indicates that students enrolled in the foundation course were performing as would be expected based on their Grade 11 English marks and that having been enrolled in foundation English did not account for much of the variance in their grades.

Mathematics: Two hundred and seventy one students were enrolled in the Mathematics credit course in the Fall and 82 in the foundation course. Of this 


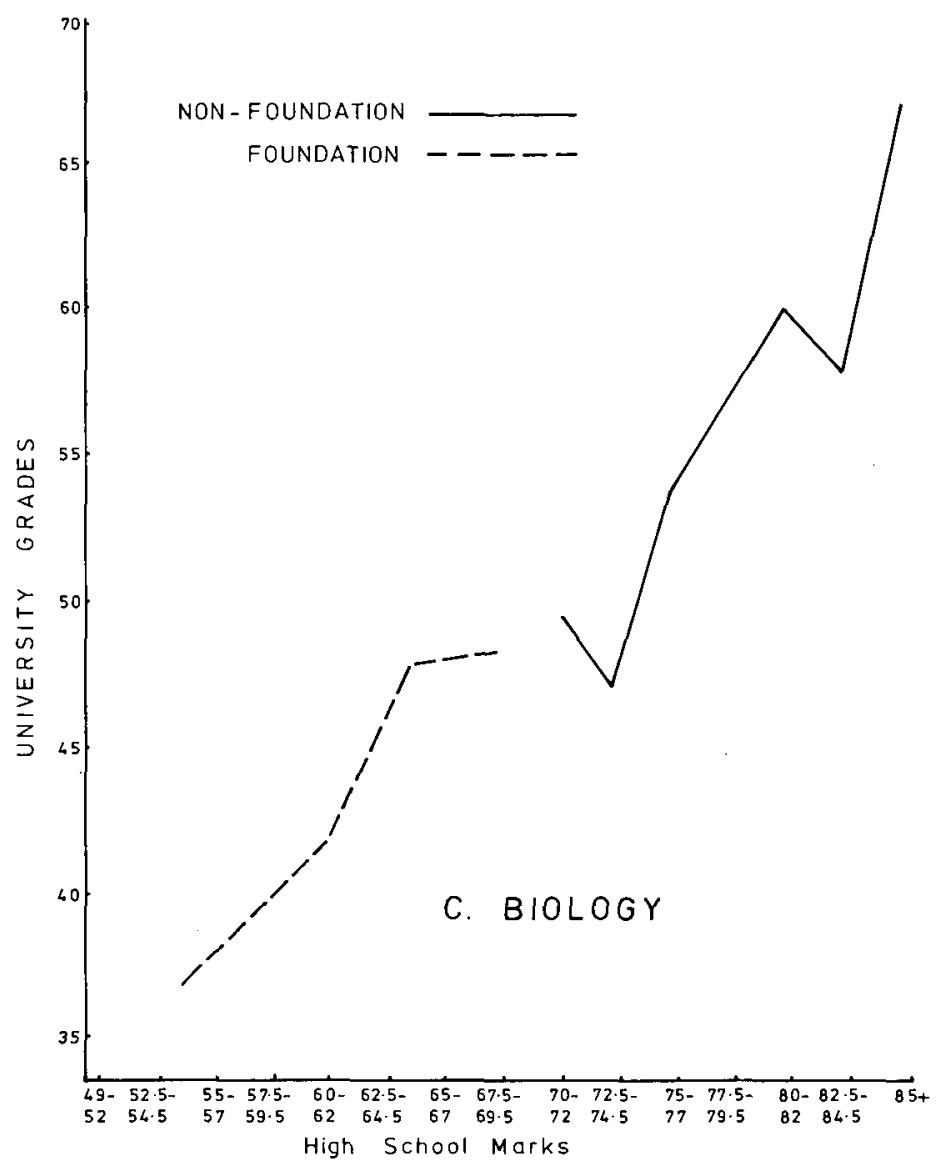

Figure 2C University grades plotted against high school marks in Biology.

latter group, 12 failed the course and reenrolled in the Winter semester, 25 dropped the course and 45 students enrolled in the credit course offered in the Winter. The relationship between Grade 11 Mathematics marks and university Mathematics marks in the credit course, for foundation and non-foundation students, can be seen in Figure 2B.

As can be seen in Table 2, the full model accounts for slightly more than $18 \%$ of the variance in university Mathematics grades. The interaction was not significant $(F=1.43 ;$ d.f. $=1,305 ; p>.10)$ which means that the slope $(.61)$ of the grades which the foundation students obtained in their Mathematics credit course was not significantly different from the slope (.91) of the Fall credit course grades. Removing the quadratic component from the equation indicates that it contributed $1 \%$ of the variance $(F=2.33 ;$ d.f. $=2,305 ; \mathrm{p}=.08)$. Removing the course from the equation and leaving the linear component reduces the variance accounted for by $.66 \%(\mathrm{~F}<1)$. Thus, university grades were not related to which of the courses the student had taken (foundation-credit adjusted mean $=56.01$, 


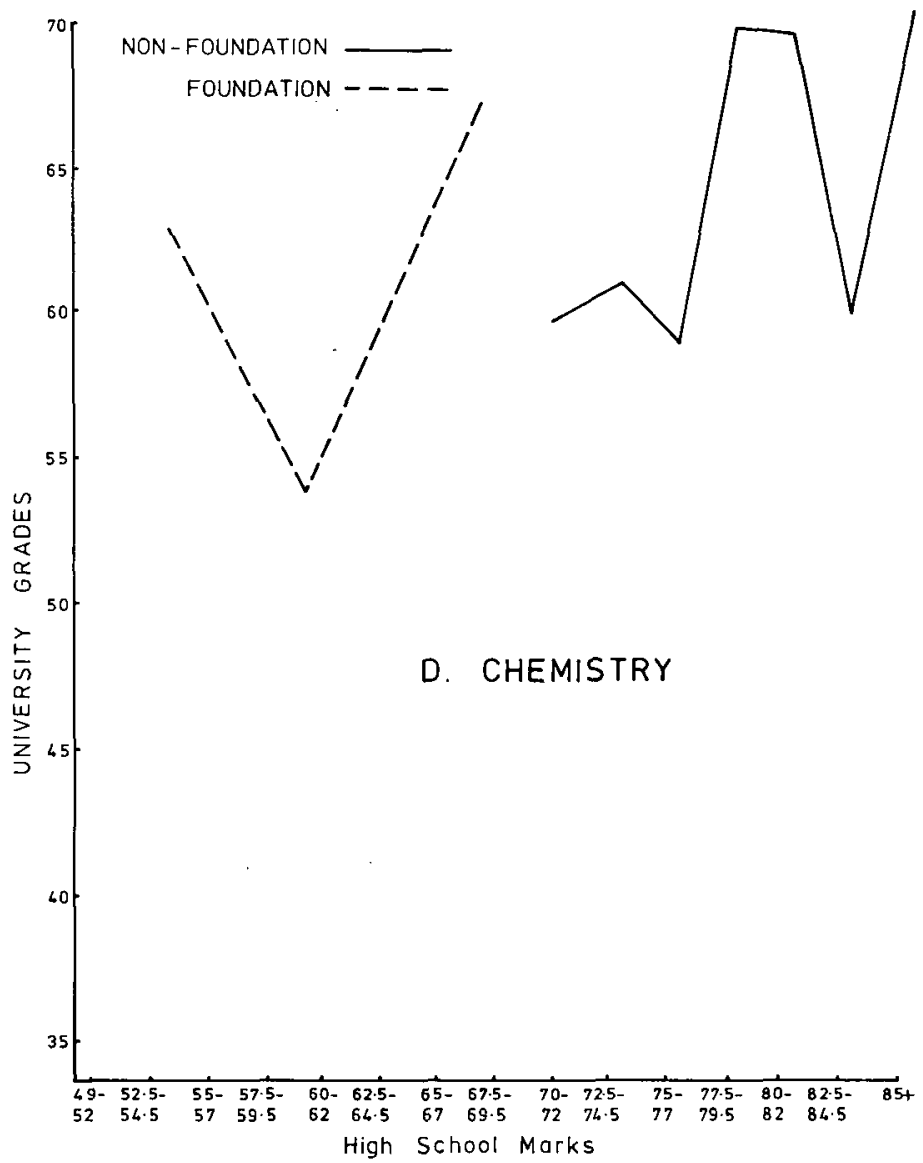

Figure 2D University grades plotted against high school marks in Chemistry.

credit adjusted mean $=54.63)$. However, when the linear component was removed and only the course was left, the variance was reduced by $13 \%$. Although the quadratic component might be considered marginally significant the linear relationship between high school grades and university grades was clearly the major contributor and the only significant contributor to the overall variance $(F=16.61 ;$ d.f. $=3,313 ; \mathrm{p}<.01)$. This indicates that students enrolled in the foundation course were performing as would be expected based on their Grade 11 Mathematics marks and that having been enrolled in foundation Mathematics did not account for much of the variance in their grades.

Biology: One hundred and twenty three students were enrolled in the Biology credit course in the Fall and 48 in the foundation course. Of this latter group, 1 failed the course and reenrolled in the Winter semester, 16 dropped the course and 31 students enrolled in the credit course offered in the Winter. The relationship between Grade 11 Biology marks and university Biology grades in the credit course, for foundation and non-foundation students, can be seen in Figure 2C. 
As can be seen in Table 2, the full model accounts for slightly more than $52 \%$ of the variance in university Biology grades. Unlike the previous courses, the slope of the grades which the foundation students obtained in their first Biology credit course (.95) was significantly different from the slope (1.05) of the Fall credit course grades $(F=9.72 ;$ d.f. $=1,132 ; \mathrm{p}<.01)$. (The interaction accounted for $3 \%$ of the overall variance.) Removing the quadratic component from the equation indicates that it contributed $.48 \%$ of the variance $(F=66.69$; d.f. $=2,132 ; \mathrm{p}<.01)$. Removing the course enrolled from the equation and leaving the linear component reduces the variance accounted for by less than $1 \%(\mathrm{~F}<1)$. When the linear component was removed and only the course was left, the variance was reduced by $4 \%(F=3.74 ;$ d.f. $=3,312 ; p<.01)$.

The results indicate that although the interaction, the linear and the quadratic components were significant contributors to the overall variance it was the quadratic component which accounted for the greatest portion of the variance. It is also clear that the course in which a student was enrolled did not have a strong effect on his or her performance.

Chemistry: Fifty nine students were enrolled in the Chemistry credit course in the Fall and 30 in the foundation course. Of this latter group, 2 failed the course and reenrolled in the Winter semester, 12 dropped the course and 16 students enrolled in the credit course offered in the Winter. The relationship between Grade 11 Chemistry marks and university Chemistry grades in the credit course, for foundation and non-foundation students, can be seen in Figure 2D.

As can be seen in Table 2, the full model accounts for slightly more than $25 \%$ of the variance in university Chemistry grades. As in the case of Biology the slope of the grades which the foundation students obtained in their first Chemistry credit course (.96) was. significantly different from the slope (.78) of the Fall credit course grades $(F=12.09 ;$ d $f .=1,116 ; p<.01)$. (The interaction accounted for $7 \%$ of variance.) Removing the quadratic component from the equation indicates that it contributed $14 \%$ of the variance $(F=11.15 ;$ d.f. $=2,116 ; p<.01)$. Removing the course enrolled from the equation and leaving the linear component reduces the variance accounted for by $2 \%(F=1.54 ; d . f .=3,116 ; p>.10)$. When the linear component was removed and only the course was left, the variance was reduced by $1 \%(F=1.54 ;$ d.f. $=3,116 ; p>.25)$.

While the results indicate that the interaction and quadratic components were significant contributors to the overall variance it was the quadratic component which accounted for the greatest portion of the variance. It is also clear that the course in which a student was enrolled did not have a strong effect on his or her performance.

It is interesting to note that in a previous analysis, when the quadratic component was not included in the regression equation, the interaction and the course in which the student was enrolled accounted for significant portions of the variance. When the quadratic component is included as in the present analysis it is clear that the difference between classes in the original analysis were due to the curvilinear relationship between the variables. 
$\mathrm{R}^{2}$ Values Used in Assessing the Variance in University Grades Accounted for.

\begin{tabular}{|c|c|c|c|c|}
\hline & English & Mathematics & Biology & Chemistry \\
\hline Total model & .25711 & .18405 & .52607 & .25531 \\
\hline Without interaction: a & .25672 & .18021 & .49114 & .17769 \\
\hline $\begin{array}{l}\text { Without quadratic: a } \\
\text { Basic model }\end{array}$ & .25610 & .17161 & .04717 & .11221 \\
\hline Without linear: & .10938 & .04154 & .03970 & .09285 \\
\hline Without class: & .25608 & .16500 & .00683 & .08258 \\
\hline
\end{tabular}
a. Removed from total model without being replaced
b. Replaced after being removed.

\section{Secondary Analysis}

An analysis of covariance (ANCOVA) was used to evaluate the impact of foundation courses on students who had not taken the subject in high school. For these students overall Grade 11 average was used as the covariate. The first analysis involved a comparison of the university grades of those who had taken a subject in high school to the grades of those who had not taken the same subject in high school.

There was no difference in the grades obtained in foundation Biology by students who had or had not taken Biology in high school $(F=.84$; d.f. $=1,51$; $\mathrm{p}=.36)$. Similarly, there was no difference in the grades which they obtained in their subsequent credit Biology credit course $(F=2.48 ;$ d.f. $=1,31 ; \mathrm{p}=.12)$. As noted earlier the number of students in each of these groups is very small ( $\mathrm{N}=54$ for foundation grade comparison and $\mathrm{N}=34$ for credit grade comparison). Thus, no conclusions can be drawn about the relative impact of the Biology foundation course on these two groups.

In Chemistry, unlike Biology, there was a marked difference between the performance of these two groups of students. In the foundation Chemistry course students who had taken the subject in high school did significantly better (Mean $=63.5)$ than did students who had not taken the subject in high school (Mean = $45.83)(\mathrm{F}=28.12 ;$ d.f. $=1,87 ; \mathrm{p}<.001)$. In the subsequent Chemistry credit course those who had taken the subject in high school (Mean $=60.63)$ continues to outperform those who had not taken the subject in high school (Mean $=46.76)$ $(F=5.486 ;$ d.f. $=1,30 ; p=.03)$. Since the primary analysis indicated that foundation Chemistry did not improve performance above what would have been expected based on high school marks it is likely that the difference observed 
in the secondary analysis is attributable not to the foundation course itself, but to the prior exposure to the subject matter of the students who had taken the subject in high school.

The second analysis involves a comparison of the credit course grades of students who were first put into the foundation course with the grades of those who were put directly into the credit course. In both Biology and Chemistry there was no difference in grades in the credit course between the performance of students who had not taken the subject in high school and were assigned to the foundation course and the performance of students who had not taken the subject in high school and were assigned directly to the credit course. Again, the number of students in these categories was very small (Biology $=14$, Chemistry $=33$ ) so an assessment of the impact of these foundation courses is not possible.

Even though the number of students involved was small, the trend was for the students $(\mathrm{N}=16)$ who were assigned directly to the credit Physics course to do better in the credit course (Mean grade $=65$ ) than the students $(\mathrm{N}=5)$ who were assigned to the foundation course before going into the credit course (Mean grade in credit course $=55)(\mathrm{F}=3.787 ;$ d.f. $=1,18 ; \mathrm{p}=.067)$. Thus, it does not appear that in Physics there is any benefit for a student in being assigned to the foundation course, on the contrary, those who are assigned directly to the credit course do better even when their superior high school average is controlled for.

The last of the secondary analysis is of the grades of students who took a subject in high school and who were below the cut-off line but for the reasons mentioned earlier were assigned directly to the credit course. There is no difference between the credit course grades in English, Mathematics of Biology for students below the cut-off line who go into the foundation course in the subject and those who go directly into the credit course. It does not appear, however, that students who go directly into the credit course in Chemistry perform as well (Mean grade $=55.36)$ as do dtudents who first go into the foundation Chemistry course (Mean credit course grade $=60.63)(F=4.20 ;$ d.f. $=1,41 ; p=.05)$. This result is in contrast to the primary analysis which indicated that Foundation Chemistry did not improve performance beyond what would have been expected based on high school marks. However, the difference observed in the secondary analysis may possibly be due to the curvilinear relationship between high school Chemistry marks and university Chemistry marks which was found in the primary analysis.

\section{DISCUSSION}

Given the results of the analysis of the foundation courses and the nature of the foundation courses, i.e., no course credit give, and the potential long term effect of having been required to enroll in one, e.g., an extra semester in university, based on both the primary and secondary analysis it does not seem that there is any justification for continuing to require students to enroll in foundation courses in their present format. A question could, perhaps, be raised about the power of the statistical tests which were performed given the small sample size, particularly 
in Biology and Chemistry. However, in terms of the variance accounted for by each component in the regression equation in the primary analysis it is clear that in all cases the course in which a student is enrolled accounts for a trivial portion of the variance (never greater than $2 \%$ ). While increasing the sample size might increase the likelihood of obtaining statistical significance it would not necessarily increase the portion of the variance accounted for by the different components.

The role of programme evaluation does not end with determing whether or not a programme is having the desired effect. On the basis of the evaluation, recommendations should be made about retaining, changing or terminating a programme. ${ }^{4}$ When the recommendation is that changes be made the directions of the changes may be suggested by the results of the evaluation. In the present case the results of this evaluation, when taken in conjunction with those of Sullivan and Wilson (1980) suggest the direction in which changes could be made.

Sullivan and Wilson reported on an academic upgrading programme which stands in contrast to the foundation programme in that it was successful for Arts students (but not for Science students). The academic upgrading programme described by Sullivan and Wilson was administered at Grenfell College, a regional college in Corner Brook associated with Memorial University. The foundation programmes described in the present article were administered on the main campus of Memorial University which is located in St. John's. Although there are regional differences between the campuses on which the two programmes were tested the populations which were exposed to the two programmes are quite similar, both coming from the same high school system. It is interesting to speculate on the characteristics of the two programmes and the differences between Arts and Sciences which led to one programme having been successful with Arts students and one not having been successful with either Arts or Science students.

As described earlier, foundation courses are non-credit courses which are required of students who have low grades in a particular subject. Thus, this approach involves dealing with remedial education in a particular subject area in which the student is judged to be deficient. The Basic Academic Skills Programme (BAS) described by Sullivan and Wilson, was not a credit course either, however, it was not required (marginal students were encouraged to take the course). The main difference between the two programmes appears to be in the skills emphasized and the degree of coordination between the instructors. The BAS programme emphasized, as the name implies, basic skills. In fact, faculty members teaching the other courses in which the BAS students were enrolled would subtract marks for poor English, poor language use and mistakes in calculations regardless of the content of their specific course, i.e., Psychology, History, etc. Faculty members who taught the BAS met at least once a week to discuss the programme and the students in the programme.

One is led to the conclusion that it is both the emphasis on basic skills and the coordination between faculty which led to the success of the BAS programme with Arts students. While in foundation English basic skills may be emphasized, 
the faculty in areas other than English make no effort at coordination. (Indeed, many complain when they are asked to subtract marks for poor grammar or spelling).

What of Science Students? Sullivan and Wilson speculate that the abilities associated with success in Arts are different than those necessary for success in Science. Although there is no direct evidence from the present study, there does appear to be some evidence that the relationship between high school performance and university performance is different in the two areas. As was seen in the primary analysis, in both English and Mathematics the linear relationship between high school marks and university grades accounted for most of the variance in university performance. On the other hand, in both Biology and Chemistry it was the quadratic (or curvilinear) relationship between high school marks and university grades which accounted for most of the variance in university performance. In addition there does appear to be some evidence in Chemistry that repeated exposure to the subject matter improves performance. Students who took Chemistry in high school, no matter what their mark, obtained better Chemistry grades in first year university than did those who had not taken the course in high school. Further, students whose marks in high school were low appear to suffer when put directly in the credit course (i.e., they do not have the repeated exposure which comes from having taken the foundation course).

While this evidence says nothing about the abilities needed for success in the two areas it does suggest that different skills are needed for success in the two areas. First, from Sullivan and Wilson's results it seems that emphasis on basic skills is an aid in academically upgrading students in the Arts. Second, the quadratic relationship found in the primary analysis suggests that the underlying skills which aid the student in high school in the Sciences do not carry over in a simple fashion to aid the student in university in the Sciences. Further, based on the trend in Chemistry, it appears that repeated exposure may play an important role in academic upgrading in the Sciences.

To summarize, the evaluation described in this paper led to the recommendation to the university administration that the remedial education programme not be continued in its present format. If changes were to be implemented then the results of this evaluation, when taken in conjunction with those of Sullivan and Wilson pointed to new directions to be explored.

\section{FOOTNOTES}

1. We wish to thank Dr. G. Skanes for the assistance which he gave with the multiple regression analysis and Dr. A. Sullivan for his helpful comments on the manuscript.

2. Since almost all students in the sample who has been assigned to foundation Physics had not taken Physics in high school, Physics was not included in any analysis.

3. At the time the evaluation was conducted Grade 11 was the last year of high school. This system is currently being changed.

4. Based on the analysis reported in this article the administration appointed a committee to examine the question of foundation courses. 
15 A Regression Discontinuity Analysis of a Remedial Education Programme

\section{REFERENCES}

Campbell, D.T., \& Stanley, J.C. Experimental and Quasi-Experimental Designs for Research. Chicago: Rand McNally, 1966.

Cook, T.D., \& Campbell, D.T. Quasi-Experimentation, Design and Analysis Issues for Field Settings. Chicago: Rand MacNally, 1979.

Sullivan, A.M., \& Wilson, P. A Successful academic upgrading programme Follow-up over five semesters. Canadian Journal of Higher Education, 1980. 